\title{
Vitiligo and skin cancer: what's the link?
}

\section{Aida Oulehri, Sara Elloudi, Hanane Baybay, Zakia Douhi, Fatima Zahra Mernissi}

\author{
Department of Dermatology, University Hospital Hassan II, Fez, Morocco
}

Corresponding author: Aida Oulehri, MD, E-mail: aidaoulehri@gmail.com

\begin{abstract}
It is well established that ultraviolet (UV) radiation is one of the major risk factors for the development of skin cancer. It is therefore consistent to think that in vitiligo plaques completely devoid of melanin and melanocytes, cellular DNA without its natural protector can only be more vulnerable to UV aggression. We logically expect to have a high incidence of skin cancer in vitiligo patients. To our astonishment, the literature tends rather towards the hypothesis that there is no increase in this risk. We report a new case of multiple actinic keratoses, Bowen's disease and squamous cell carcinoma on the sun-exposed areas in a 67 year old man with universal vitiligo. We also conducted a literature review by collecting all similar cases as well as cohorts, meta-analyses and literature reviews on the issue, to determine if this debate is still ongoing.
\end{abstract}

Key words: Actinic keratoses; Bowen disease; Squamous cell carcinomas; Universal vitiligo; Carcinogenesis

\section{INTRODUCTION}

Vitiligo is an acquired chronic depigmenting disorder of the skin resulting from selective destruction of melanocytes. It's the most frequent cause of depigmentation worldwide, with an estimated prevalence of $1 \%$ [1]. The etiology is unknown, although several hypotheses have been proposed in the literature, the leading theory is still the autoimmune etiology linked to specific genetic mutations. Vitiligo is clinically characterized by the development of white macules in the skin or hair, or both. Two forms of the disease are well recognized; segmental and non-segmental vitiligo (the commonest form). The universal form is defined by a depigmentation that reaches between 80 and 90 percent of the skin area [2].

The risk of developing skin cancer in patients with vitiligo is still a debated issue. We report multiple cutaneous malignancies concurrence in vitiligoaffected skin, on the sun-exposed areas in a patient with widespread vitiligo. We also conducted a literature review to analyze this controversial association.

\section{CASE REPORT}

A 78 year old patient, farmer with heavy and chronic sun exposure, followed for chronic lymphoid leukaemia for 7 years, currently in remission and presenting a universal vitiligo evolving for 60 years never treated. The patient consulted for multiple erosive and hyperkeratotic lesions of the scalp and face (Figs. la and lb). The patient also had a history of left parietal squamous cell carcinoma resected a year ago (Fig. 2). Clinical and dermoscopic examination found multiple actinic keratoses and multiple lesions suspected of malignancy. We mapped all the lesions we judged suspicious and then we took multiple biopsies. They showed three squamous cell carcinomas and four Bowen's diseases (Figs. 3 and 4). The extension workup had objectified a right laterocervical adenopathy suspected of malignancy, the cervicotomy of which confirmed a lymph node metastasis of a squamous cell carcinoma. The patient was treated with lymph node dissection with concomitant removal of malignant skin lesions.

\section{DISCUSSION}

The cutaneous squamous cell carcinoma (SCC) is the second most common non melanoma skin

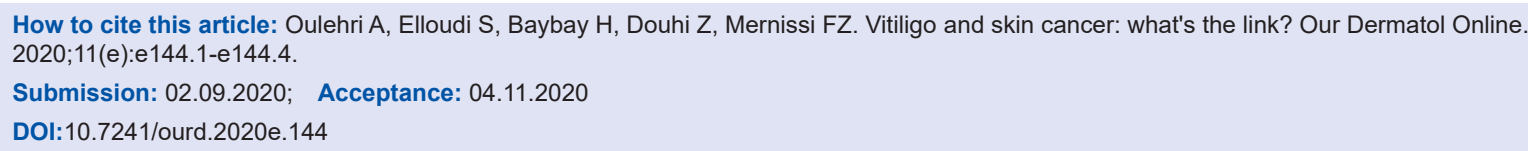




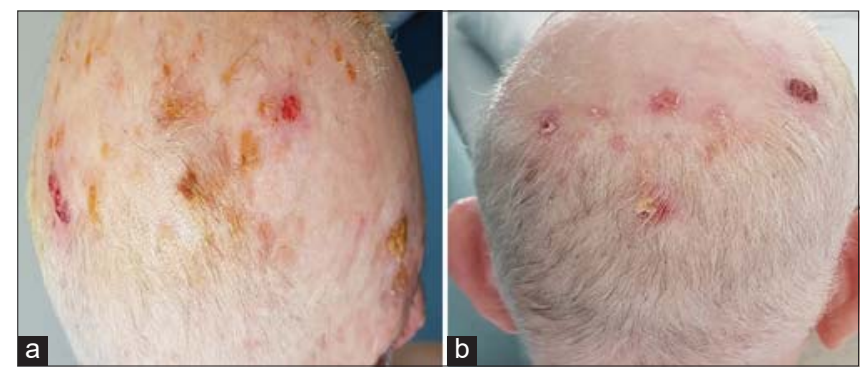

Figure 1: ( $a$ and $b)$ Multiple erosive and hyperkeratotic lesions of the scalp and face.

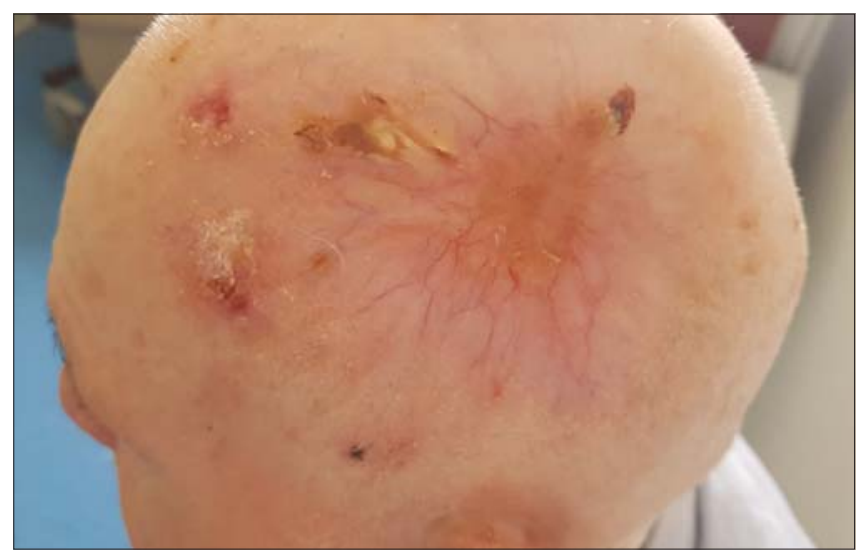

Figure 2: Resection site of the former squamous cell carcinoma.

cancer after basal cell carcinoma (BCC) and in some studies approaches the incidence of BCC. The most significant risk factors that predispose to the development of cutaneous SCC include age, male sex, immunosuppression, light skin (Fitzpatrick skin type's I-III), exposure to sunlight or other ultraviolet radiation [3]. In fact, a linear correlation has been shown between SCC and UV radiation exposure. Accordingly, the incidence of SCC has been reported to double with each $8-10^{\circ}$ decline in the geographical latitude and equator [4]. Additionally, it is well known that delayed effects of sun exposure, such as development of skin cancer and photo-aging, are pronounced in people with fair skin. At the molecular level, UV produces DNA damage, gene mutations, immunosuppression, oxidative stress and inflammatory responses, all of which have an important role in photo-aging [5]. Through the accumulation of these mutations and other cellular changes, an area of skin (in response to ultraviolet light damage) can progress through increasing levels of dysplasia and transform into a SCC [3] .

We also know that melanin is one of the protective agents of cellular DNA against UV. The low incidence of cutaneous malignancies in darker skinned groups is primarily a result of photoprotection provided

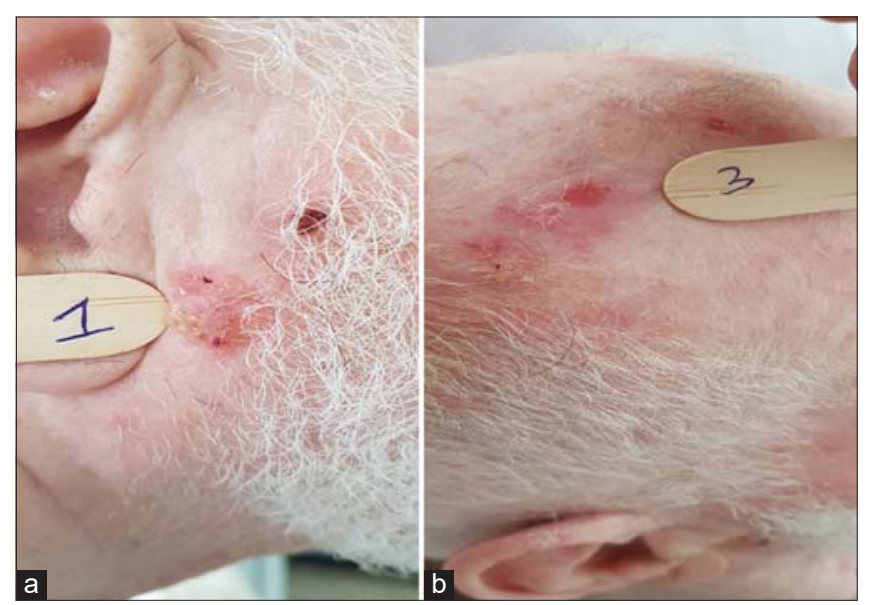

Figure 3: $(a$ and $b)$ Two clinical images corresponding to two bowen diseases confirmed on histology.

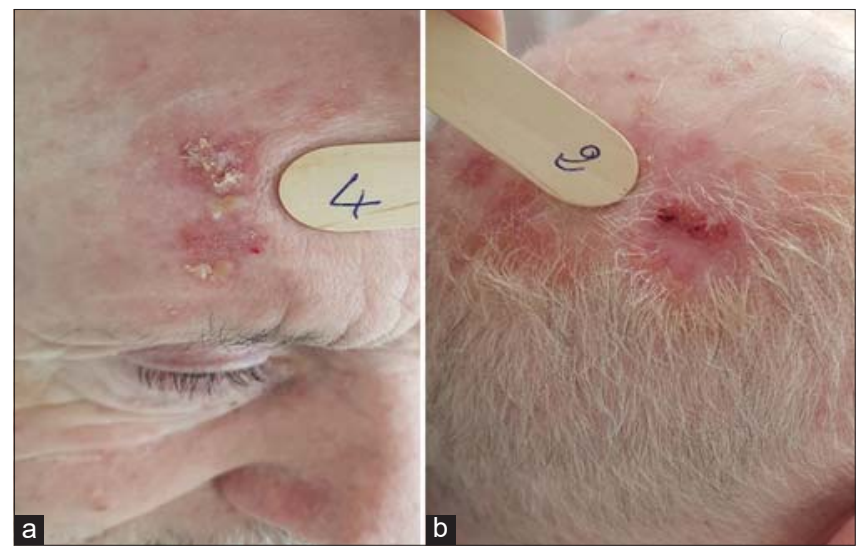

Figure 4: ( $a$ and $b)$ Two clinical images corresponding to two Squamous cell carcinomas confirmed on histology.

by increased epidermal melanin which provides an inherent sun protection factor (SPF) of up to 13.4 in blacks [5] .This is because the larger, more melanized melanosomes in the epidermis of dark skin absorb and scatter more light energy than the smaller, less melanized melanosomes of white skin. The dose of UV radiations required to produce a minimally perceptible erythema has been estimated to be 6-33 times greater in blacks than in whites [3].

Vitiligo skin is considered to be more sensitive to sun exposure than poorly pigmented skin because of the complete lack of a melanin barrier. In fact, Due to the absence of melanin in lesional skin there is a theoretical concern that there might be a higher risk of skin cancer in people with vitiligo. However, reported cases of skin cancer occurring in long-lasting vitiligo are rare, and only six such cases have been reported since 2000 (Table 1).

All the writings were case reports of a single patient, squamous cell carcinoma was much more frequent 
www.odermatol.com

Table 1: All reported cases of skin cancer occurring in in vitiligo-affected skin

\begin{tabular}{|c|c|c|c|c|c|c|c|c|}
\hline Reference & $\begin{array}{c}\text { Year of } \\
\text { publication }\end{array}$ & $\begin{array}{c}\text { Number of } \\
\text { patients }\end{array}$ & $\begin{array}{c}\text { Patient age/ } \\
\text { gender }\end{array}$ & $\begin{array}{l}\text { Type of } \\
\text { vitiligo }\end{array}$ & $\begin{array}{l}\text { Duration } \\
\text { of vitiligo }\end{array}$ & $\begin{array}{l}\text { Type of pre- } \\
\text { cancerous lesions }\end{array}$ & $\begin{array}{l}\text { Type and number } \\
\text { of skin cancer }\end{array}$ & Site lesions \\
\hline [11] & 2000 & 1 & $68 / M$ & Universal & 45 & Multiple AKs & $1 \mathrm{SCC}$ & $\begin{array}{l}\text { Whole upper } \\
\text { extremity and neck }\end{array}$ \\
\hline [12] & 2000 & 1 & $98 / F$ & Generalized & 58 & AKs & $1 \mathrm{SCC}$ & $\begin{array}{l}\text { Scalp, left forearm } \\
\text { and face. }\end{array}$ \\
\hline [13] & 2001 & 1 & $72 / F$ & Generalized & 45 & Multiple AKs & $1 \mathrm{SCC}$ & Face \\
\hline [4] & 2012 & 1 & $65 / M$ & Generalized & 30 & Non & $1 \mathrm{SCC}$ & $\begin{array}{l}\text { Back side of the } \\
\text { right hand }\end{array}$ \\
\hline [14] & 2018 & 1 & $84 / \mathrm{M}$ & Generalized & 40 & Multiple AKs & 2 SCC 1 BCC & Face \\
\hline [15] & 2019 & 1 & $65 / F$ & Generalized & 20 & None & $1 \mathrm{BCC}$ & The back \\
\hline Our case & 2020 & 1 & 76/M & Universal & 56 & Multiple AKs & $4 \mathrm{BD} 3 \mathrm{SCC}$ & Scalp and face \\
\hline
\end{tabular}

SCC: Squamous cell carcinoma; BCC: Basal cell carcinoma; AKs: Actinic keratoses; BD: Bowen's diseases.

than basal cell carcinoma, precancerous lesions and mainly actinic keratoses were also very frequent, all of the lesions were in photoexposed areas mostly the face and neck, the sex ratio was 1 , all had an age above 65 years with the exception of a single case and finally all patients presented a long evolution of generalized vitiligo. All these characteristics were also found in our patient, the particularity of our case was the presence of multiple lesions. A history of chronic myeloid leukemia could also be an additional risk factor.

A prospective study was conducted to validate the possible influence of cumulative UV exposure in developing early photodamage and non-melanoma skin cancer (NMSC) in vitiligo. The results confirmed the absence of an expected high risk for sun-induced damage and skin cancer in a large group of patients with vitiligo. They propose that there may be a direct association between this results and an increased functional wild-type p53 expression in vitiligo patients [6]. Two cohort studies have retrospectively evaluated the lifetime prevalence of melanoma and NMSC in patients with vitiligo $[7,8]$ they showed that patients with vitiligo have a decreased risk of developing skin neoplasms of both melanoma and NMSC, even considering that a larger proportion in this patient group is exposed to higher levels of ultraviolet radiation.

Some studies have also shown that the genetic and autoimmune profiles of vitiligo patients may confer a degree of protection against the development of melanoma and NMSC [9]. A recent systematic review supports the current view that vitiligo may be protective of skin cancer. This could be due to the genetic and autoimmune profile of vitiligo, or the fact that patients with vitiligo are more careful regarding sun protection than those without vitiligo [10].

\section{CONCLUSION}

The low number of case reports as well as the results of the different cohorts and literature reviews is reassuring as to the risk of developing skin cancer on vitiligo.

Nevertheless, recent case reports are increasing, cumulative UV in patients with vitiligo may still be a risk factor for nonmelanoma skin carcinoma (NMSC), and we can; based on the literature highlight some risk factors such as age and extended form.

We must remain vigilant with our vitiligo patients; continue to advise photoprotection and regular monitoring.

\section{Consent}

The examination of the patient was conducted according to the principles of the Declaration of Helsinki.

The authors certify that they have obtained all appropriate patient consent forms, in which the patients gave their consent for images and other clinical information to be included in the journal. The patients understand that their names and initials will not be published and due effort will be made to conceal their identity, but that anonymity cannot be guaranteed.

\section{REFERENCES}

1. Ezzedine K, Eleftheriadou V, Whitton M, van Geel N. Vitiligo. The Lancet. 2015;386:74-84.

2. Iannella G, Greco A, Didona D, Didona B, Granata G, Manno A, et al. Vitiligo: Pathogenesis, clinical variants and treatment approaches. Autoimmun Rev. 2016;15:335-43.

3. Gloster HM, Neal K. Skin cancer in skin of color. J Am Acad Dermatol. 2006;55:741-60.

4. Verma P, Singal A, Sharma S, Dhawan A. Squamous cell carcinoma complicating vitiligo in an Indian man. J Cutan Aesthet Surg. 2012;5:36.

5. Narayanan DL, Saladi RN, Fox JL. Review: Ultraviolet radiation and skin cancer: UVR and skin cancer. Int J Dermatol. 2010;49:978-86.

6. Schallreuter KU, Tobin DJ, Panske A. Decreased photodamage and low incidence of non-melanoma skin cancer in 136 sun-exposed caucasian 


\section{www.odermatol.com}

patients with vitiligo. Dermatology (Basel). 2002;204:194-201.

7. Paradisi A, Tabolli S, Didona B, Sobrino L, Russo N, Abeni D. Markedly reduced incidence of melanoma and nonmelanoma skin cancer in a nonconcurrent cohort of 10,040 patients with vitiligo. J Am Acad Dermatol. 2014;71:1110-6.

8. Teulings HE, Overkamp M, Ceylan E, Nieuweboer-Krobotova L, Bos JD, Nijsten T, et al. Decreased risk of melanoma and nonmelanoma skin cancer in patients with vitiligo: a survey among 1307 patients and their partners. Br J Dermatol. 2013;168:162-71.

9. Rodrigues M. Skin Cancer Risk (Nonmelanoma Skin Cancers/ Melanoma) in Vitiligo Patients. Dermatologic Clinics. 2017;35:129-34.

10. Ban L, Labbouz S, Grindlay D, Batchelor JM, Ratib S. Risk of skin cancer in people with vitiligo: a systematic review and meta-analysis. Br J Dermatol. 2018;179:971-2.

11. Saarinen K, Lestringant GG, Masouye I, Frossard PM. Actinic damage and squamous cell carcinoma in sun-exposed skin affected by vitiligo. Br J Dermatol. 2000;143:219-21.

12. Akimoto S, Suzuki Y, Ishikawa O. Multiple actinic keratoses and squamous cell carcinomas on the sun-exposed areas of widespread vitiligo. Br J Dermatol. 2000;142:824-5.

13. Seo S-L, Kim I-H. Squamous cell carcinoma in a patient with generalized vitiligo. J Am Acad Dermatol. 2001;45:S227-9.

14. Zhang XT, Ma XH, Jin WW, Chen SS, Xu HT. Concurrence of multiple cutaneous malignancies on sun-exposed vitiligo skin of a patient: A case report and review of the literature. Indian J Dermatol. 2018;63:346.

15. Fiszon-Cerqueira L, Ramos-e-Silva M, Guerreiro FB, CistaroSerrano M, Carneiro AHC, Gomes MK. Giant basal cell carcinoma associated with vitiligo. Clin Case Rep. 2019;7:1782-6.

Copyright by Aida Oulehri, et al. This is an open access article distributed under the terms of the Creative Commons Attribution License, which permits unrestricted use, distribution, and reproduction in any medium, provided the original author and source are credited.

Source of Support: Nil, Conflict of Interest: None declared. 